\title{
Compression of mortality: the evolution in the variability in the age of death in Latin America
}

\author{
Marcos Roberto Gonzaga, \\ Universidade Federal do Rio Grande do Norte (UFRN) \\ marcosrg@ccet.ufrn.br \\ Bernardo L. Queiroz, \\ Universidade Federal de Minas Gerais (UFMG) \\ lanza@cedeplar.ufmg.br \\ Everton E. Campos De Lima, \\ Universidade Estadual de Campinas (UNICAMP) \\ everton@nepo.unicamp.br
}

\begin{abstract}
In this paper, we investigate the evolution of the mortality age profile and the distribution of age at death in a series of Latin America countries. Latin America presents an interesting case study because of the peculiarities of epidemiological and health transitions. We use data from different and alternative sources to investigate the compression of mortality in Latin America. We concentrated our analysis in three main points. First, we evaluate the quality of data that underlie national-level mortality overtime in LAC countries. Second, we estimated an adequate age pattern of mortality for Latin America. Third, we analyze the evolution of the distribution of deaths over age and time in order to identify the effects of changes on the variability of age at death. The results indicate that the quality of mortality data is improving over time for all countries included in this study. We also find a reduction in variability of age at death, and that the reduction was faster for females than males.
\end{abstract}

Keywords: mortality, Latin America, compression, variability, data quality 


\section{Introduction}

The transition of mortality in developed countries, especially Western Europe, has demonstrated, albeit with some controversy, the importance of economic development, mediated by improvements in living standards for the historical decline of mortality in these populations (McKeown and Record, 1962; Preston, 1975; Cutler and Miller, 2005; Cutler, Deaton and Lleras-Muney, 2006).

Much of the reductions in mortality would be consequence, at first, of improvements in the levels of nutrition and economic development, with some improvement in public health (Fogel, 1986, Preston, 1975). In a second stage, public health would take a more prominent role, with improvement in sanitary conditions (Cutler and Miller, 2005) and practical personal care being the main determinants. Finally, from the mid-twentieth century, medical interventions, through development of vaccinations and antibiotics for the treatment of diseases are the most prevalent factors (Cutler, Deaton and Lleras-Muney, 2006).

A consequence of those historical declines in mortality of developed countries was a reduction on the variability of age at death (Wilmoth and Horiuchi, 1999) as part of a process related to what Fries (1980) called the compression of mortality hypothesis. The main idea, developed by Fries, is that survival curves would become rectangular when mortality levels decline. That is, since death concentrate in a narrow age interval, the slope of survival curve in that range becomes steeper, and the curve itself begins to appear rectangular suggesting that human life expectancy is approaching its maximum potential value (Fries, 1980; Wilmoth, 1997; Wilmoth and Horiuchi, 1999). Following Fries (1980), several authors have examined empirical evidence related to his hypothesis (Meyers and Manton, 1984a, 1984b; Go et al, 1995; Nusselder and Mackenbach, 1996; Wilmoth, 1997; Paccaud et al, 1998; Wilmoth and Horiuchi, 1999; Cheung et al; 2005; Edwards and Tuljapurkar, 2005; Cheung and Robine, 2007). The main interest of most researchers is the relation between the compression-rectangularization of the survival curve to the biological limits to the human life span. However, Wilmoth (1997) and Wilmoth and Horiuchi (1999) argue that the compression-rectangularization process is related for a reduction in the variability of age at death that can happen while the distribution of age at death is moving to the right. In this case, the existence of biological limits to the human life span implicates a compression- 
rectangularization process, but a compression-rectangularization happening does not implicate in biological limits to human lifespan (Wilmoth, 1997; Wilmoth and Horiuchi, 1999).

More recent developments suggest two processes of changes in the distribution of age at death: changes in variability and the shifting of mortality (Bongaarts and Feeney, 2003; Bongaarts, 2005; Canudas-Romo, 2008; Zureick, 2010; Bergeron-Boucher, 2015). While the variability focus on how concentrated is the distribution of deaths around the modal or mean age at death, shifting mortality means that the variability of age at death remains constant even as life expectancy continues to increase.

In this paper we focus on the Latin American and Caribbean (LAC) countries' experience related to the compression of mortality hypothesis. Making extensive use of Latin America Human Mortality Database, Latin America Mortality Database, Human Mortality Database and World Health Organization database, we concentrated our analysis in three main points. First, we evaluate the quality of data that underlie national-level mortality overtime in LAC countries. Second, based on a model proposed by Himes, Preston and Condran (1994) we estimated an adequate age pattern of mortality for Latin America in order to use it in a relational model to fit and extrapolate the mortality rates from 5 to 110 years old, by sex, for all LAC countries over various time periods (staring year in parenthesis): Chile (1920), Mexico (1930), Brazil (1980), Argentina (1970), Colombia (1964), and Peru (1972), Costa Rica (1963), Puerto Rico (1970), Panama (1960), Guatemala (1964), Cuba (1970), Dominican Republic (1960), and Uruguay (1960). Finally, using some well-known empirical measures of the compression of mortality hypotheses we analyze the evolution of the distribution of deaths over age and time in order to identify the effects of changes on the variability of age at death. We also compared our results with estimations from the Latin American Mortality Database (Lambda, 2015) ${ }^{1}$.

In Latin American, the decline in mortality did not follow the historical course observed in developed countries. In little more than a half century most LAC countries experienced major changes in health conditions related to structures demographic, socioeconomic and

\footnotetext{
${ }^{1}$ http://www.ssc.wisc.edu/cdha/latinmortality/
} 
environmental processes as a result of rapid industrialization and urbanization (Palloni, 1981 Palloni and Wyrick, 1981; Palloni, 1985; Palloni, Hill and Pinto-Aguirre, 1996; Palloni and Pinto-Aguirre, 2011). In a recent paper, Palloni and Pinto-Aguirre (2011) produce estimates of mortality curves for Latin America and investigate the contribution of changes in causes of deaths to improvements in life expectancy and how socioeconomic factors are related to changes in mortality levels. Several authors indicate that the mortality transition in Latin America began around 1930 to 1940, when the transition process in developed countries was already in a much more advanced stage (Palloni, 1981; 1985). Although the rapid transition of mortality is an intrinsic feature of Latin America, there are arguments for some diversity in the process causing some countries initiate the transition before others (Palloni, 1981; 1985). Only after 1950 began a widespread reduction in mortality in Latin America, thus reducing the gap with developed countries (Palloni 1981).

Parallel to the mortality transition, epidemiological transition in Latin America occurs in a context of heterogeneous health profile, where different countries were at different stages of transition (Frenk et al, 1990). It is unlikely, however, that any of these countries are experiencing a transition stage similar to that of many developed countries (Omran, 1971; 1982). The overlapping stages, the resurgence of some diseases that had been controlled and a peculiar epidemiological polarization, both between countries and between different geographical areas and population sub-groups within a country, it would rank the epidemiological transition in Latin America as a template and extended polarized transition (Frenk et al., 1990; Schramm et al. 2004; Araújo, 2012). The intrinsic process of epidemiological transition in some countries produces a scenario where the incidence of communicable diseases in adult and advanced ages is relatively high compared to developed countries (Frenk et al 1990). Guatemala, for example, would be a more pre-transitional stage, with a high proportion of causes of death from diseases, while countries such as Mexico, Chile and Uruguay, were in more advanced stages (Brevis et al, 1997). Among these last three countries, Mexico present a longer transition situation similar to that observed in Brazil (Chaimowicz, 1997), while Chile, Uruguay would be closer to a post-transitional stage (Brevis et al, 1997). 
Changes in mortality and morbidity patterns are responsible for increases in life expectancy and reductions in the variability of age at death in Brazil (Gonzaga, Queiroz and Machado, 2008). Those changes follow a similar pattern as observed in the developed countries (Wilmoth and Horiuchi, 1999) and can be explained by an improvement in living conditions that reduced the number of deaths caused by infectious diseases, leading to an increase in the participation of non-infectious diseases as the main causes of deaths and a change in the age pattern of mortality (Schramm et al, 2004). At the same time, one can observe a increase in mortality due to violence and transit accident in some LAC countries as Brazil and Mexico (Nadanovsky et al., 2009; Waiselfisz, 2012; Aburto et al., 2016).

On the other hand, one can observe a decline in the mortality rates of the elderly population leading to an increase in the oldest age at death (Campos and Rodrigues, 2004). They also suggest that this phenomenon is still under way, in Brazil, and one could expect further decline in the mortality rates at older ages. If people are living longer, including at older ages, serious doubts exist about the overall health conditions of the population. In more developed countries there is a debate about compression of morbidity hypothesis and alternative views on the association between mortality, morbidity and population health (Manton, 1982; Olshansky et al, 1991; Crimmins and Beltran-Sanchez, 2011).

In contrast to epidemiological transitions and mortality in developed countries, the peculiarities of these transitions in Latin American countries suggest some less optimist conjectures for the future longevity of the population (Palloni and Pinto-Aguirre, 2004; 2011, Palloni et al., 2005). Will some LAC countries experiencing a reduction in the variability of age at death concomitant displacement of these deaths for ages more go along? How recent changes in the profile of causes of deaths, especially increase in external causes of deaths, could affect trends in the variability of age at death in Latin America? In addition, how could these changes inform mortality forecast? In this sense, the paper discusses old paradigms of mortality studies in Latin America (data quality) and new paradigms (variability of age at death). 


\section{Data and Methods}

\subsection{Mortality Data}

In order to estimate age mortality pattern in Latin American Countries we make extensive use of the death and population data available on Human Mortality Database $(\mathrm{HMD})^{2}-$, Latin American Human Mortality Database $(2013)^{3}-$, and the World Health Organization (WHO) database ${ }^{4}-$. In addition to LAHMD, we use mortality data obtained from the HMD and WHO database for Chile, Costa Rica, Puerto Rico, Cuba, Panama, Dominican Republic, Guatemala, and Uruguay. We also use data from Sweden and selected countries in Eastern Europe (Bulgaria and Russia), obtained from the Human Mortality Database. We include data for Eastern Europe countries to compare the evolution of mortality and trends in the variability of age at death in Latin America with countries that are also facing rapid changes in the mortality profile.

\subsection{Death Distribution Methods}

The first step of the paper is to evaluate the quality of mortality data available overtime in Latin America. For some countries and years, the information on death counts underregistration is already available at the Latin America Mortality Database (LAHMD), but it is necessary to perform quality control checks for countries not included in the database and for years preceding the availability of data in the LAHMD.

First, we evaluate the quality of age declaration data using digit preference measures, using Whipple Index (WI), and more elaborate measures to detect age heaping. We further investigate the quality of age reporting by applying several age heaping measures proposed several authors (Kannisto, 1994; Vaupel, Wang, Andreev and Yashin, 1997; Shyrock and Siegel, 2004). We also use different methods to investigate age overstatement in death registration records. In general, it is possible to identify distortions by comparing the observed age distributions to those or population register based estimates that are known as accurate (Kannisto, 1999; Jdanov, et.al, 2008)

\footnotetext{
${ }^{2}$ www.mortality.org

${ }^{3}$ www.lamortalidad.org

${ }^{4}$ www.who.org
} 
Second, we evaluate the degree of death counts registration completeness. Several methods based upon equations of population dynamics have been developed to evaluate the coverage of reported deaths relative to populations. The death distribution methods (DDM) are commonly used to estimate adult mortality in a non-stable population (Timeaus, 1991). They compare the distribution of deaths by age with the age distribution of the living and provide age patterns of mortality in a defined reference period. There are three major approaches: the General Growth Balance Methods (Hill, 1987), the Synthetic Extinct Generation method (Benneth and Horiuchi, 1981), and the Adjusted Synthetic Extinct Generation method (Hill, You and Choi, 2009). The death distribution methods make several strong assumptions: that the population is closed to migration, that the completeness of recording of deaths is constant by age, that the completeness of recording of population is constant by age and that ages of the living and the dead are reported without error.

The Bennett and Horiuchi (1981), known as Synthetic Extinct Generations (SEG) method, uses age-specific growth rates to convert an observed distribution of deaths by age into the corresponding stationary population age distribution. Since in a stationary population the deaths above each age $\mathrm{x}$ are equal to the population aged $\mathrm{x}$, the deaths in the stationary population above age $\mathrm{x}$ provide an estimate of the population of age $\mathrm{x}$. The completeness of death registration relative to population is estimated by the ratio of the death-based estimate of population aged $\mathrm{x}$ to the observed population aged $\mathrm{x}$.

The GGB method is derived from the basic demographic balancing equation, which expresses the identity that the growth rate of the population is equal to the difference between its entry rate and exit rate. This identity holds for open-ended age segments $\mathrm{x}+$, and in a closed population the only entries are through birthdays at age $\mathrm{x}$. The entry rate $\mathrm{x}+$ minus the growth rate $\mathrm{x}+$ thus provides a residual estimate of the death rate $\mathrm{x}+$. If the residual estimate can be calculated from population data from two population censuses and compared to a direct estimate using the recorded deaths, the completeness of death recording relative to population recording can be estimated (Hill, 1987; Hill, Choi and Timeaus, 2005; Hill, You and Choi, 2009). 
Hill, You and Choi (2009) proposed that the combination of SEG and GGB might be more robust than either one individually. The combined method consists of first applying GGB to estimate any changes in census coverage $(\mathrm{k} 1 / \mathrm{k} 2)$, using the estimate to adjust one or other census to make the two consistent, and then applying SEG using the adjusted population data in place of the reported.

\subsection{Estimates of death rates and survival curves by single age}

First, we estimate five-year age group death rates to deal with potential problems of age declaration for all Latin America countries. Then, we use a relational model (Himes, Preston and Condran, 1994; Palloni and Pinto-Aguirre, 2011) to fit and extrapolate the mortality rates from 5 to 110 years old for all countries, years and sex for all Latin American countries. That strategy allows us to produce a linear relationship between a logit transformation of the observed death rates and the same transformation in "standard" death rates. Then, the age pattern of mortality in the population under study can be expressed as the following linear function:

$$
\Psi_{\mathrm{j}, \mathrm{t}}(\mathrm{x})=\alpha_{\mathrm{j}, \mathrm{t}}+\beta_{\mathrm{j}, \mathrm{t}} \Psi_{\mathrm{s}}(\mathrm{x})
$$

Where: $\Psi_{\mathrm{j}, \mathrm{t}}(\mathrm{x})$ is a logit transformation of the death rate at age $\mathrm{x}$ in population $\mathrm{j}$ and year $\mathrm{t}$; $\Psi_{\mathrm{S}}(\mathrm{x})$ is a logit transformation of the death rate at age $\mathrm{x}$ in the standard and $\alpha_{\mathrm{j}, \mathrm{t}}, \beta_{\mathrm{j}, \mathrm{t}}$ are parameters to be estimated for each population and year.

In order to apply the relational model in (1) we need to find a "good standard" that can express the mortality pattern for LAC. After get the pattern we can use (1) in order to estimate the mortality rates for each country and year (separately by sex).

The strategies that we used to find the LAC Standard Mortality Patterns was very similar to that proposed by Himes, Preston and Condran (1994). Based on the pooled data with observed adjusted mortality rates by country, year, sex and age (five-year-age from 5 to $85+$ or $100+$ depend on the data availability for each country) we constructed the Standard by estimating the following ordinary least squares for each sex: 


$$
\Psi_{\mathrm{j}, \mathrm{t}}(\mathrm{x})=\delta+\sum \beta_{\mathrm{x}} \mathrm{I}_{\mathrm{x}}+\sum \lambda_{\mathrm{j}, \mathrm{t}} \mathrm{C} \mathrm{Y}_{\mathrm{j}, \mathrm{t}}
$$

Where, $\Psi_{\mathrm{j}, \mathrm{t}}(\mathrm{x})$ is a logit transformation of the observed death rates in the country $\mathrm{j}$ and year $\mathrm{t}$; $\mathrm{I}_{\mathrm{X}}$ is a dummy variable for age $\mathrm{x}$ ( $=1$ if the death rates relates to age $\mathrm{x}, 0$ otherwise). Since we have five-age intervals, we have considered the middle of each five-age intervals from 7.5, 12.5 , to 107.5 . Then we have 20 dummies for age. $\mathrm{CY}_{\mathrm{j}}$ is a dummy variable for a combination between country $\mathrm{j}$ and year $\mathrm{t}$ ( $=1$ if the death rates relates to country/year $\mathrm{j}, \mathrm{t}$ and 0 otherwise). Since we have 38 country/year combinations we have 37 dummies. Argentina/1920 were omitted as reference categories for country and year. The $\delta, \beta_{\mathrm{x}}, \lambda_{\mathrm{j}, \mathrm{t}}$ are appropriate parameters that need to be estimated.

After estimation of the model (2) we have one $\beta$ coefficient for each age and one $\lambda$ coefficient for each country/year combination. In order to get a logit of the standard death rate at age $\mathrm{x}$ from $7.5,12.5, \ldots$, to 102.5 exact years old we used the mean of the $\lambda$ coefficients to obtain a predict value for the entire sample. Then, following Himes, Preston and Condran (1994), we used weighted least squares regression to fit and extrapolated the logit of the standard death rates from age 5 to 110 (one-year-age interval). The weights are the number of observations (country/period combinations) available for each age.

Those adjusted and extrapolated logit standard rates, by single ages, were used on the relational model in equation (1) to get smoothed logit death rates by sex and single ages for each country and year. Finally, to recover the age-specific death rates for each country/year we used the following relation:

$$
\widehat{\mathrm{M}}_{\mathrm{j} ; \mathrm{t}}(\mathrm{x})=\frac{1}{\left(1+\mathrm{e}^{\widehat{\widetilde{\Psi}}_{\mathrm{j}, \mathrm{t}}(\mathrm{x})}\right)}
$$

Where: $\widehat{\Psi}_{\mathrm{j}, \mathrm{t}}(\mathrm{x})$ is a smoothed logit death rate in the country $\mathrm{j}$, year $\mathrm{t}$ and age $\mathrm{x}$ and $\widehat{\mathrm{M}}_{\mathrm{j} ; \mathrm{t}}(\mathrm{x})$ is a smoothed death rate in the country $\mathrm{j}$, year $\mathrm{t}$ and age $\mathrm{x}$.

\subsection{Variability of Age at Death: alternative measures}


The historical decline in mortality rates in developed countries has two clear effects: the reduction in the variability of age at death and concentration of deaths at older ages (Nusselder and Mackenbach, 1996; Wilmoth and Horiuchi, 1999; Kannisto, 2000; Cheung et al, 2005; Edwards and Tuljapurkar, 2005). Most of the reduction in the variability can be explained by mortality decline among young age groups, especially infant and child mortality; and the concentration of deaths at older ages by structural changes, and medical advances that reduce mortality by non-infectious diseases (Wilmoth and Horiuchi, 1999; Cheung et al, 2005). In fact, early and late deaths have different implications on variability of age at death (Engelman, Canudas-Romo and Agree, 2010; Engelman et al., 2014). However, in the Latin American Countries it is not yet known whether the ongoing process of mortality decline will lead to the same situation.

The interquartile range (IQR) based on the survival function $\left(l_{x}\right)$ is a leading indicator of the variability of age at death (Wilmoth and Horiuchi, 1999). Together with measures of central tendency of age at death, the IQR has been used to evaluate the compression of mortality hypothesis (Fries, 1980). The IQR measures the concentration of deaths between first and second quartile around median age at death. All we need to do is to find the exact ages where survival function is equal 0,75 e 0,25 , respectively. Then the age range between $l_{x}=0,75$ and $l_{x}=0,25$ represents the IQR. Van Raalte, and Caswell (2012) provide a detail overview of different methods to calculate lifespan variation and its limitations.

Another measure of variability of age at death that can be easily interpretable is based on the shortest age interval in which a given proportion of deaths in a life table takes ${ }^{5}$ (Kannisto, 2000). Both IQR and C50 are correlated with themselves and with another measure of variability of age at death. Our choice for these two measures is based on its simplicity in terms of calculation and interpretation. Also, as argued by Kannisto (2000), since IQR and C50 give us an age interval in which half of all deaths take place, it is of interest to compare the results from both measures.

\footnotetext{
${ }^{5}$ To be comparable with IQR we chose the measure C50 (i.e. shortest age interval in which $50 \%$ of deaths takes place).
} 
The medium and modal age at death are the central indicator of length of life that can be evaluate together with IQR and C50, respectively. Details about calculation of IQR and C50 using life table functions can be found in Wilmoth and Horiuchi (1999) and Kannisto (2000).

\section{Results}

\subsection{Completeness of Death Counts Coverage}

The quality of mortality data in Latin America, for both males and females, improved steadily over the last half-century. In more recent years, intercensal years of 2000 to 2010, most of countries in the analysis show near complete death count registration. However, we observe wide variation over time for different countries in Latin America. For example, Brazil has showing signs of improvement since 1980. In 1980, death counts registration, in Brazil, was around $80 \%$ reaching almost $100 \%$ in 2010 . Similar trend is observed to Costa Rica. It is important to note that for a large number of countries estimates of completeness are above $100 \%$ for several years. This is related to the assumptions of the models and the overall data quality in those countries. In this paper, since we are more interested in analyzing trends in the age profile, the correct estimate of the levels of mortality is less important - since all the Death Distribution Methods adjust only the level of mortality and not the shape of the mortality age profile. The shape of the profile was adjusted when construction the survival curves by single ages.

Figure 1 and Table A1 presents the completeness of death counts for each countries, periods and sex in Latin American Countries. In general, for the earlier decades the points at young ages for both males and females are very irregular and off the fitted line, and the estimate of census coverage indicates better coverage in the first census what is consistent with problems arising from low quality, net emigration and errors in age declaration. Overall, the fit of the observations (death rates) improved over time and are relatively good for the most recent periods. The estimates are even better when fitting only for age groups 35 and above. In general, from 1990 (and for some countries since 1980) the results imply that age reporting is good and the assumptions of the methods are met. 
Figure 1- Completeness of Death Counts Coverage, Latin America, males, 1920-2010

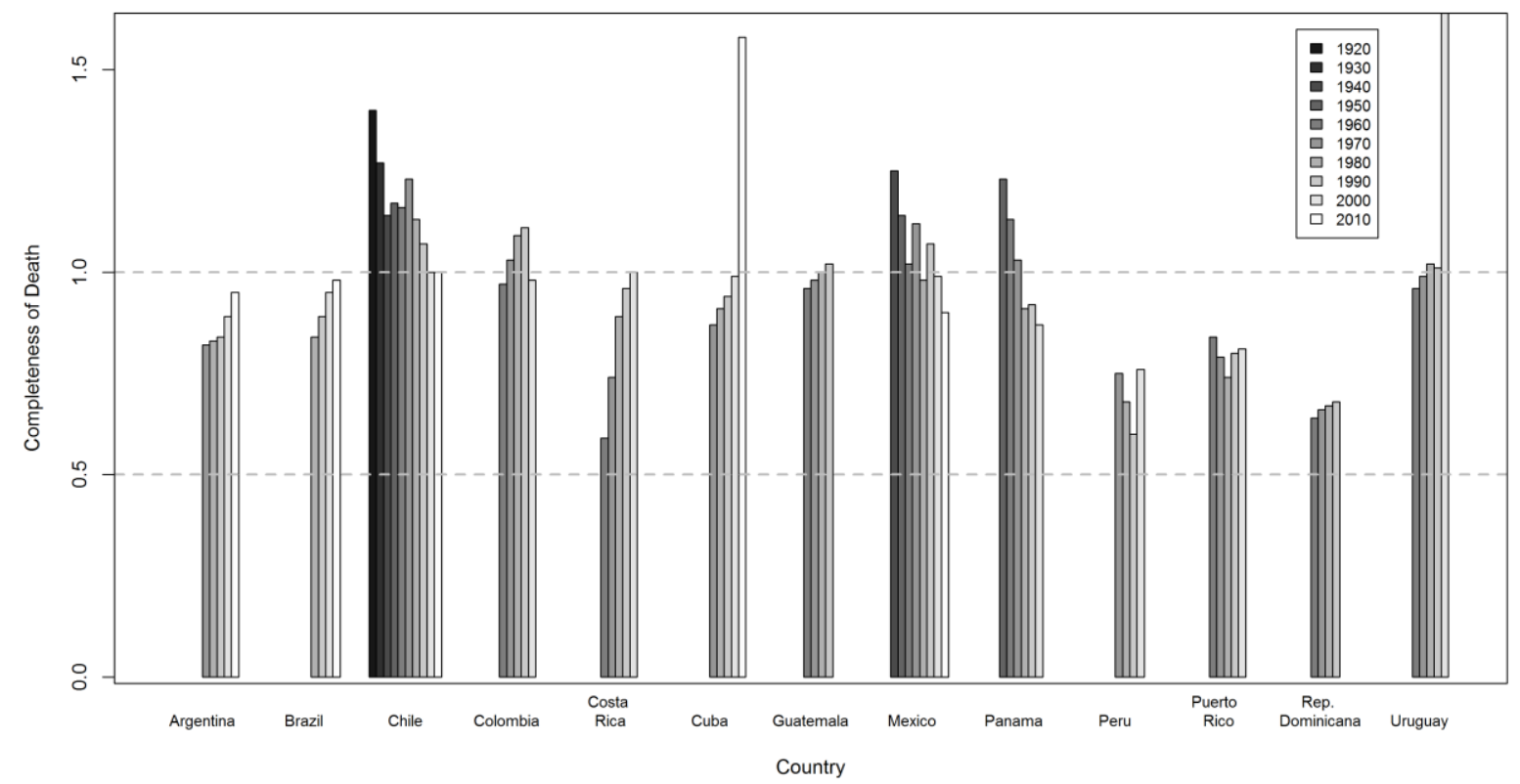

Source: Latin America Human Mortality Database (2014), Human Mortality Database (2014) and World Health Organization Database (2014)

\subsection{Evolution of Survival Curves}

Figure 2 and 3 show survival curves for males and females, respectively, on periods where the data were available for each country. The changes in the age profile are clearer for Chile and Mexico that have the longer series. In both countries, for both sex, it is possible to observe a movement towards a more rectangle survival curve as it is observed in more developed countries. Since the curves do not show age groups below 5, one cannot observe the fast decline in infant and child mortality. 
The changes in mortality levels in Latin America implied in a rapid change in the life expectancy in a half-century. On average, the countries showed in the figures 2 and 3 experienced improvements on life expectancy of more than one year per decade. For instance, Mexico and Chile had the faster increase in life expectancy at birth, with gains around 4 years per decade in last half century (CELADE, 2004; Albala et al., 2011). In Brazil, the gains in was around 3,5 since 1950s but it slows down in the last decades with gains around 2,0 years per decade between 1990 and 2010 (IBGE, 1981, 2013). In fact, similar trend is observed for all countries and both sexes in the past few decades.

However, for most countries in last periods, especially for males, we see no change or even a reversal on the increasing of survival probabilities. A possible explanation of those reversals could be the increase on the mortality by external causes in most LAC countries on the last decades. There is evidence of stagnation or even a reversal on the increasing of life expectancy in some LAC countries on the last decades (Nadanovsky et al., 2009, CanudasRomo and García-Guerrero, 2013; Aburto et al., 2016). According to Aburto et al. (2016), the increase of the homicides after 2005 in Mexico could be the mainly cause of a reversal on the life expectancy increases among males and a slowdown among females around the country. According to Nadanovsky et al (2009), the rates of homicide in 2005 was one of the highest rates in the world and the variability in the rate between the county's subnational regions could be explained more due to impunity index than social economic and demographic variables. 
Figure 2- Estimated males survival curves (Sx), Latin America Countries, (1920-2010)
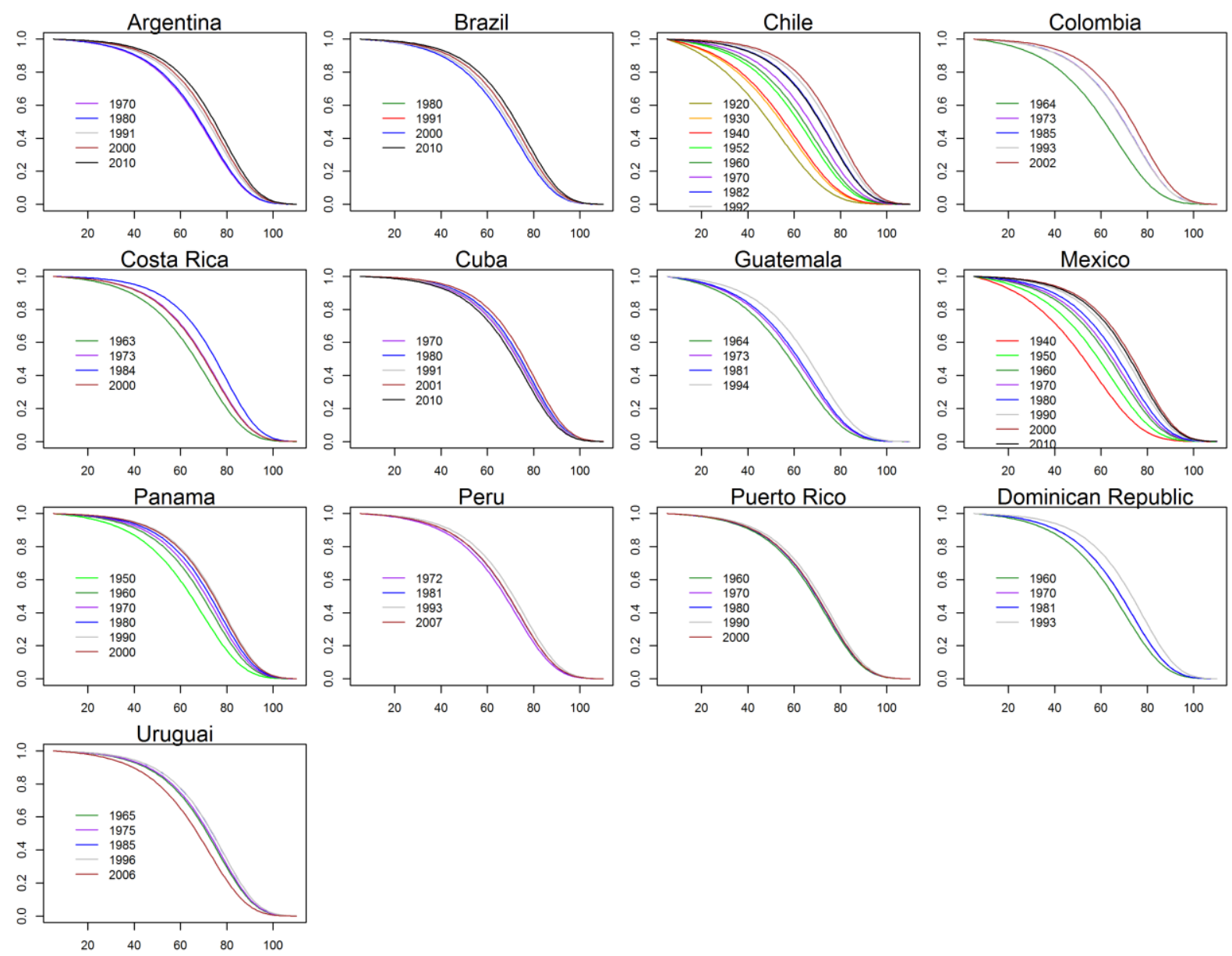

Source: Latin America Human Mortality Database (2014), Human Mortality Database (2014) and World Health Organization Database (2014)

Note: horizontal and vertical axis are ages and survival probabilities $\mathrm{S}(\mathrm{x})$, respectively.

Another possible cause for the reversal in some LAC countries, as showed in the figures 2 and 3 , could be the assumption imposed by the methods used do estimated the undercount of deaths. The recent demographic dynamics in most LAC Countries could lead to unreasonable coverage estimates by those methods. For example, in Brazil, according to Queiroz et al (2017), DDM estimates for some subnational regions showed a decrease or even an 
overreporting in deaths coverage in the last decades, a situation that is not reasonable since the quality of records in Brazil has improved since 1980 (Paes, 2005; de Mello Jorge et al., 2007; Queiroz et al., 2017).

Figure 3- Estimated females survival curves (Sx), Latin America Countries, (1920-2010)
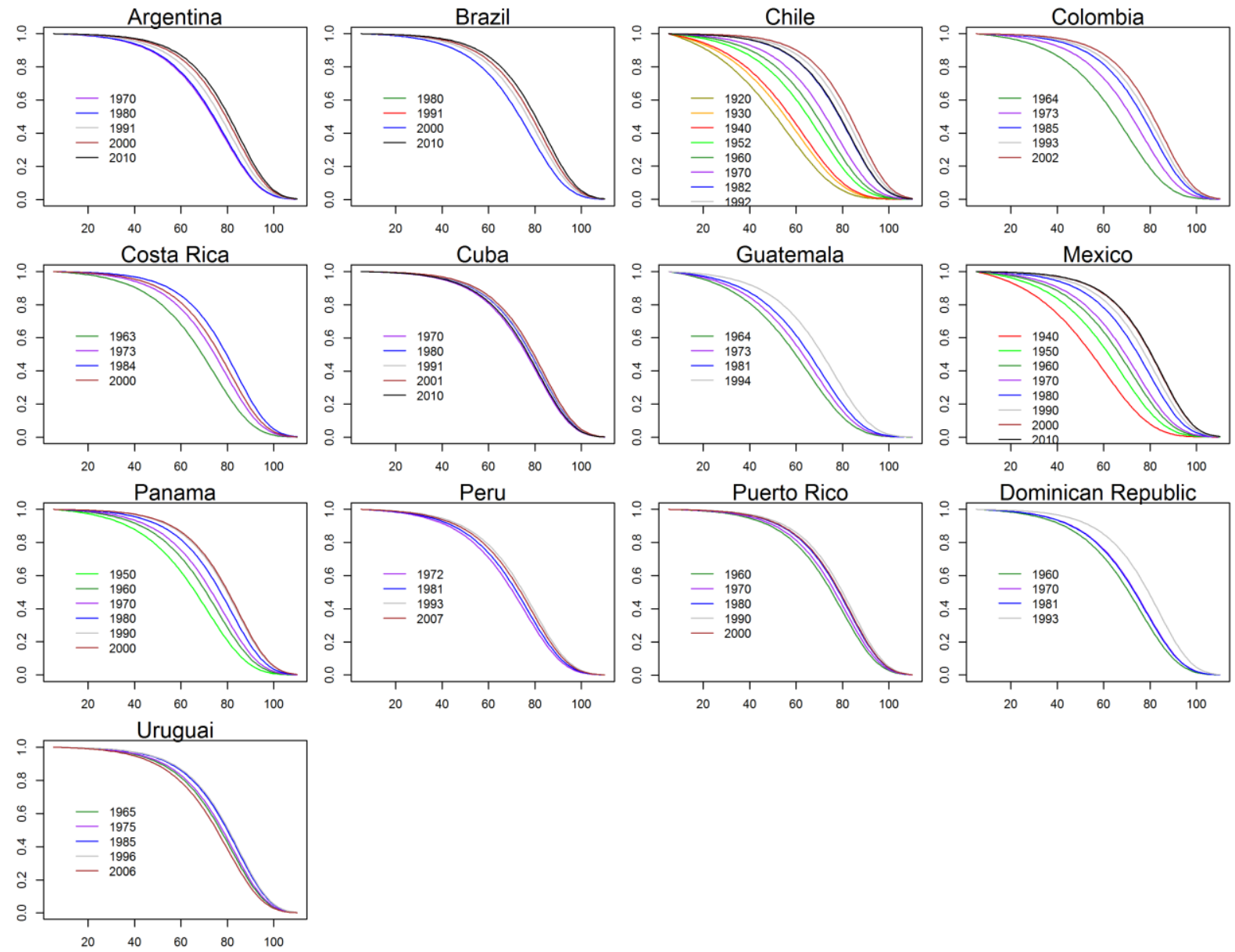

Source: Latin America Human Mortality Database (2014), Human Mortality Database (2014) and World Health Organization Database (2014)

Note: horizontal and vertical axis are ages and survival probabilities $\mathrm{S}(\mathrm{x})$, respectively.

\subsection{Variability of age at death}

As an objective and simple measure of variability of age at death we follow the recommendations by Wilmoth and Horiuchi (1999) and Kannisto (2000) and we choose the interquartile range (IQR) and the shortest age interval in which a $50 \%$ of deaths take place (C50) to analyze tendencies on the variability of age at death in LAC countries. Figures 4 and 
5 show the IQR and C50, respectively, for males and females for all LAC countries selected in this study. For comparisons purpose, we also plot estimates for Sweden (1920-2010), Bulgaria (1950-2010) and Russia (1959-2010). Sweden has experienced a historical mortality transition and has been used as a reference to explain the compression of mortality hypothesis (Wilmoth and Horiuchi, 1999). Bulgaria and Russia were selected for comparison because as LAC countries they have showed increases in mortality rates due external causes on the last half century, especially after 1989.

In the early 1920s, for both sexes, the IQR in Sweden was higher than Chile, the only LAC country with available data in the early 1900s. This higher variability in age at death could be explained by high incidence of young adult mortality due to tuberculosis (Horiuchi, 1999). It is also possible that since infant and child mortality in Chile, around 1920, were so much higher than in Sweden that those who survived the first few years of live went on to die in more concentrated ages. On the other hand, deaths in Sweden were more distributed across the age range in the same period of time, especially for young adults. For instance, in Chile significant declines in IQR starts 20 years after Sweden for both sexes. However, the levels of IQR and C50 in Sweden fell very rapidly during the following decades. Among Latin America countries the reduction in the variability of age of death follows the same path of Sweden after 1960.

Differences between IQR and C50 is generally larger in high mortality populations, as observed in LAC on the second half of the last century. Usually, for the same country, C50 can show smaller dispersion value than IQR, a result that make C50 more successful than IQR in locating the greatest concentration of deaths around a central indicator of the length of life (Kannisto, 2000). Since IQR measures variability in a percentile scale its value can be more affected by high mortality in younger ages, a situation frequently observed by populations that is passing through its mortality transition. However, as argued by Kannisto (2000) and showed in the figures 4 and 5, differences can be narrowed down substantially as the countries pass mortality transition.

For some LAC countries, one can see a clearly tendency of converge in the variability of age at death, especially for females. In Mexico, another country with a long mortality rates series, 
we also observed significant changes in the variability of age at death, with a path similar to Chile after 1940. The variability in Mexico, as measured both IQR and C50, decreased almost 8 years females and more than 5 years for males representing a significant reduction in variability in 70 years period.

It is interesting, but not surprising, that most LAC countries (including Chile and Mexico) showed a decrease followed by a stability or even an increase in IQR and C50 after 1990s or 2000s. Those remarkable reversal in LAC countries' variability of age at death in the last decades holds perhaps due to association with external causes of death that are also increasing in most LA countries, especially for males (Nadanovsky et al., 2009, Aburto et al., 2016), and that is avoiding further development of mortality compression.

In addition, according to previous studies, several features distinguish ageing process in LA countries with the process in more developed countries (Palloni and Pinto-Aguirre, 2004; 2011; Palloni et al, 2007; 2011). Due to different cohort disease regimes, the most important feature would be the difficult to predict the future health and mortality profile of the older population in LA countries (Palloni et al, 2007). The peculiarities of the mortality transition in LA countries suggests a deacceleration on longevity and points out a less optimist scenario in the future health conditions for older population (Palloni and Pinto-Aguirre, 2004; 2011).

It is also interesting to note similar paths on the variability of age at death between LA countries and Russia and Bulgaria on the last decades, especially for males. While in LA countries the increase on variability of age at death is related to increase in violence and transit accident, the main cause in Bulgaria and Russia would be the relationship between alcohol consumption and excess of premature deaths attributed to accident, suicide and violence (Mckee and Shkolnikov, 2011; Zaridze et al, 2014; Bobak et al, 2016).

The reversal on variability of age at death in the last decades are not observed only for Brazil, Argentina and Colombia. However, reductions in IQR and C50 in those countries seems to decelerate between on the last years. We need to be cautious and do not jump into harsh conclusions since data quality maybe play a role in these results. In the case of Brazil, we could hypothesize that the fastest decrease in infant mortality in the last decades (among LA 
countries) compensate for increases in adult mortality on affecting the reversal on variability of age at death.

Figure 4: Evolution in Interquartile Range (IQR), Latin America, 1920-2010
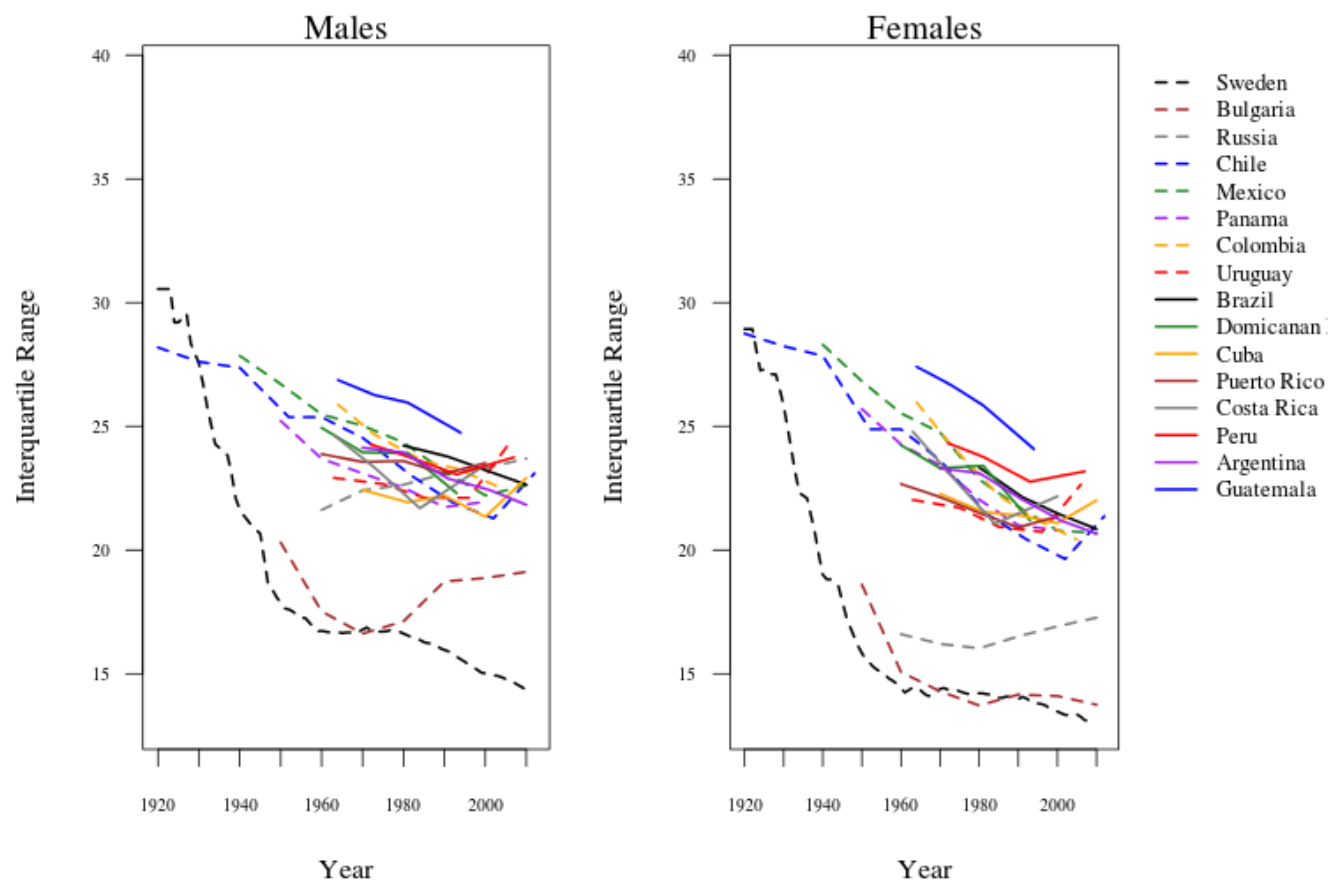

Source: Latin America Human Mortality Database (2014) and Human Mortality Database(2014) and World Health Organization (2014) 


\section{Figure 5: Evolutions in the "shortest age interval in which a $50 \%$ of deaths take place" (C50), Latin America, females, 1920-2010}
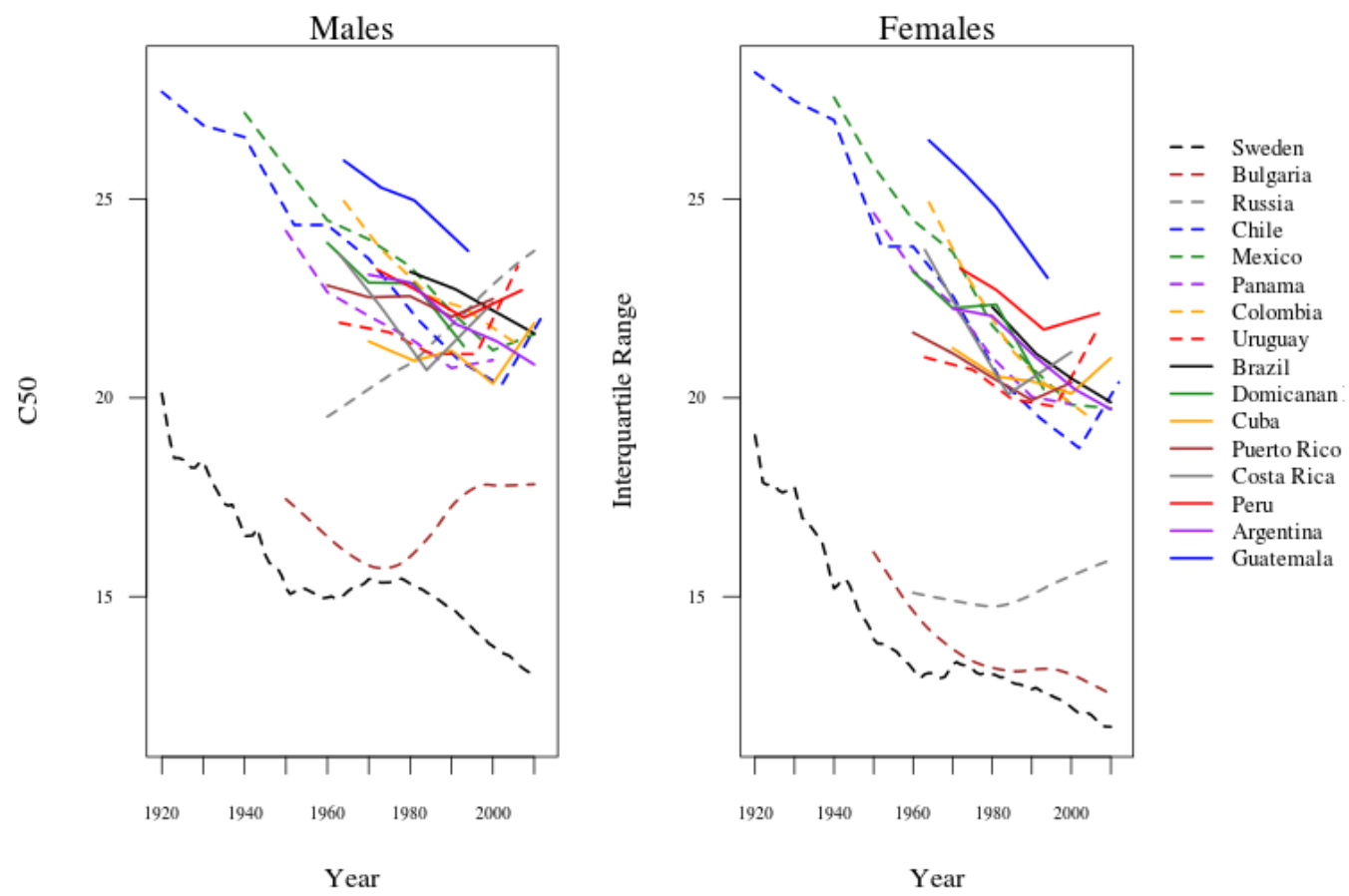

Source: Latin America Human Mortality Database (2014) and Human Mortality Database(2014) and World Health Organization (2014)

To test our estimates and results, we conduct our analysis based on an alternative source of date: Latin American Mortality Database (Lambda, 2015). The results about evolution on variability at death as measured by IQR are showed on Figure 6. Despite of differences according to the period of available data we can see similar path for longevity in LA countries based on different source of data. Results based on Lambda database do not show reversal in most LA countries as those based on LAHMD show. However, it is clear a deceleration on the decline of IQR based on data from Lambda. Sources of differences on the estimates would be based on differences in data source for observed deaths/population, methods and modeling assumptions used to correct deaths for undercounting and making adjustment for observed death rates in each country. First of all, estimations from Lambda include higher number of LA countries than LAHMD. Then, even if estimations from both data source are based on the same relational model ${ }^{6}$ one can observe different parameters estimates because of different modelling strategies. Second, different Death Distribution Methods (DDM) could be used to

\footnotetext{
${ }^{6}$ Estimation of mortality rates in Lambda, as described by Palloni and Pinto-Aguirre (2011), are still based
} on the relational model proposed by Himes, Preston and Condran (1994). 
estimate completeness of deaths. In this study we use a combination of different DDM and evaluation of the its performance estimates was based on a graphic inspection.

Figures 7 and 8 show the evolution of life expectancy at age 5 against IQR. For all countries as life expectancy at age 5 increases we observe a decline in the variability of the age at death. This finding holds with Canudas-Romo (2008) conclusion, which states the increasing modal age at death illustrates changes from a dominance of child mortality reductions to a dominance of adult mortality reductions. This process has been described as a shifting mortality process where the bulk of deaths around the modal age at death move toward older ages. Probably, this process has taken place in many Latin American and Caribbean countries for the last fifty years. However, countries in Latin America are at different stages of this transition. Peru, for example, still presents high levels of child mortality if compared to other Latin American and Caribbean countries, like Chile and Costa Rica (Guzman et al., 2006). The inverse relationship between variability of age at death life expectancy is also clear in all LA countries since increases, decreases or stagnation in life expectancy are associate with similar changes in IQR. 
Figure 6: Evolution in Interquartile Range (IQR), Latin America - Lambda, 1920-2010
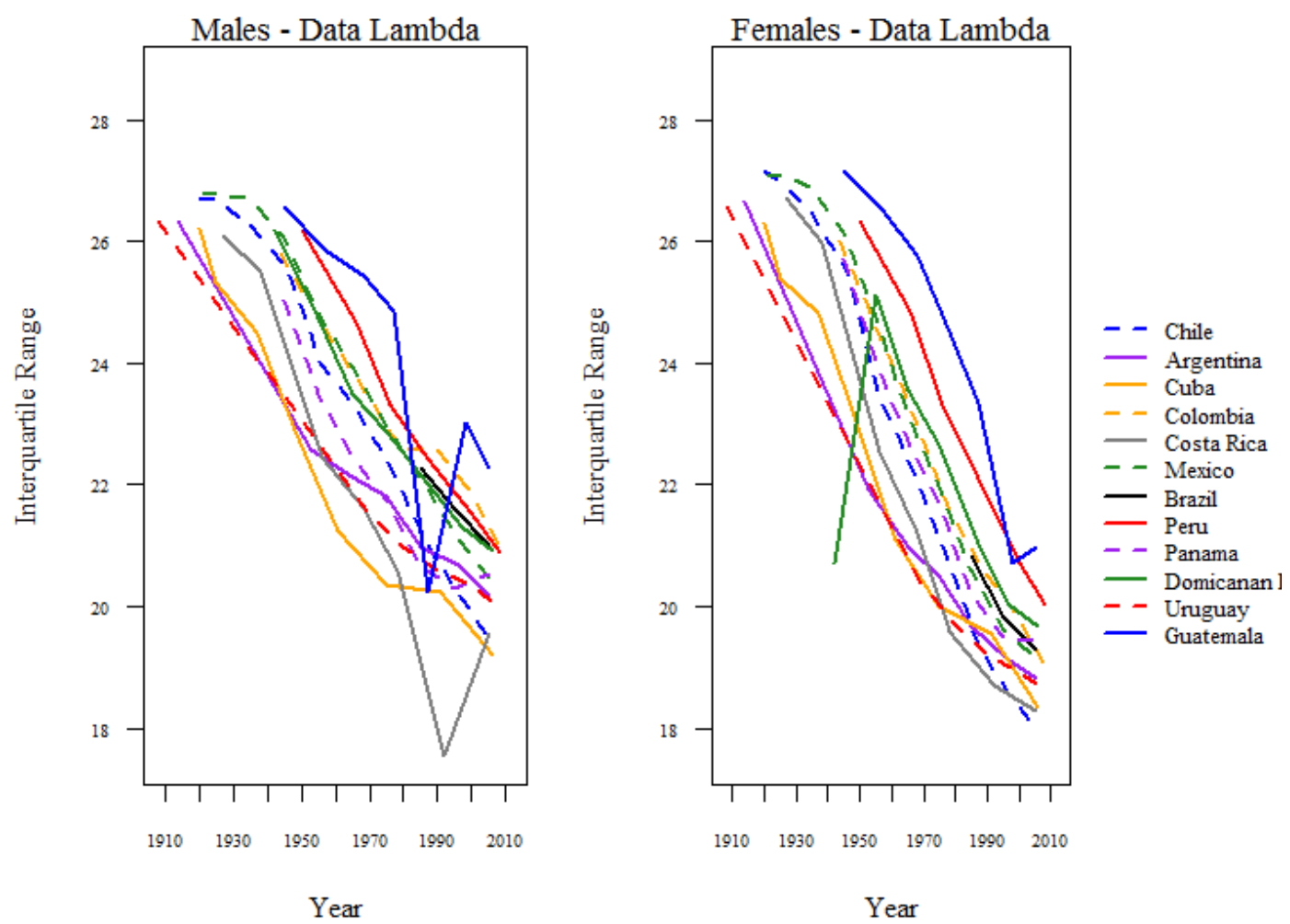

Source: Latin American Mortality Database (Lambda, 2015). 
Figure 7: Interquantile range and life expectancy at age 5, Latin America, 1920-2010, males
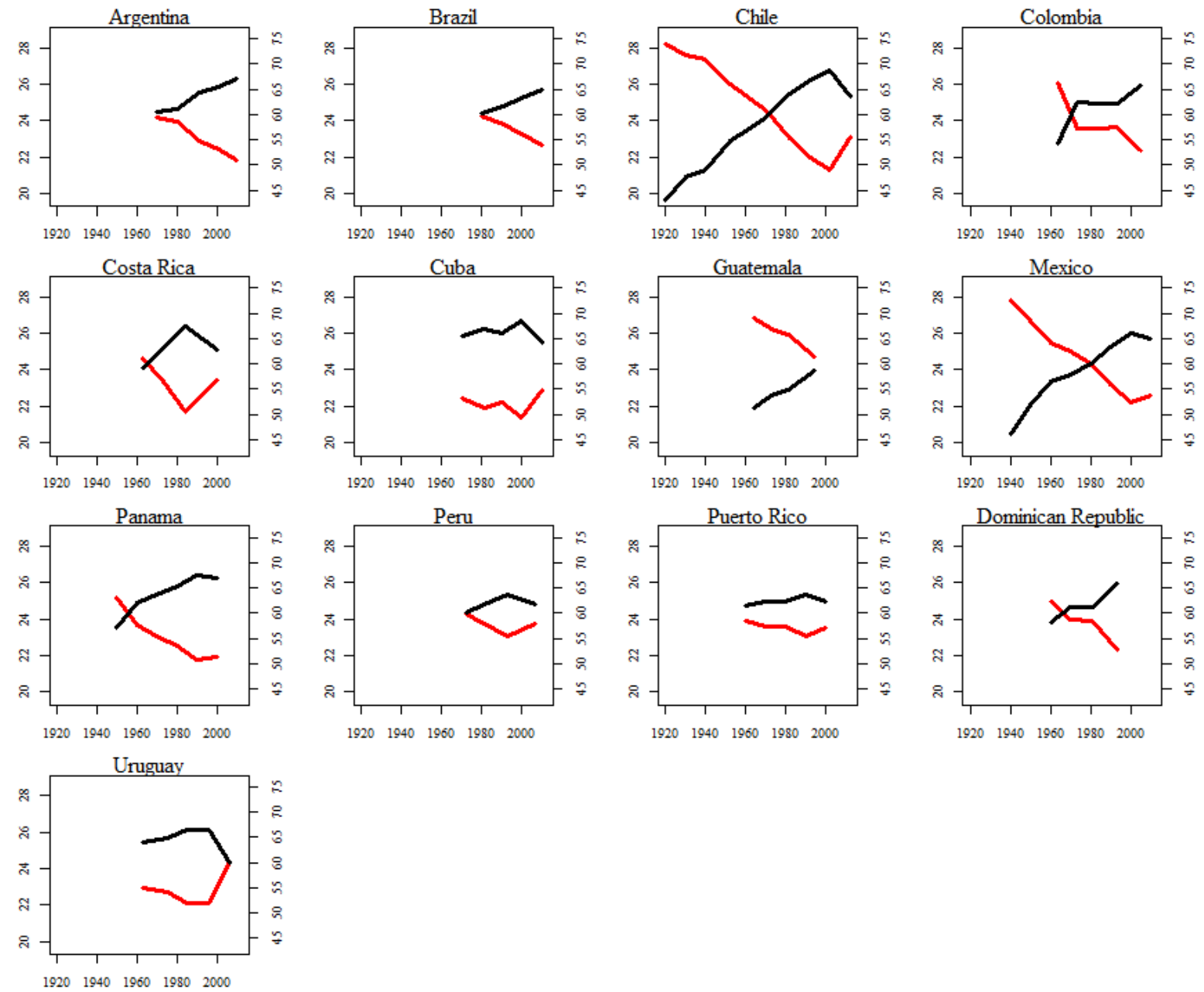

Source: Latin America Human Mortality Database (2014), Human Mortality Database (2014) and World Health Organization Database (2014)

Note: Right and left vertical axis are IQR and Life Expectancy at age 5 - e(5), respectively. Horizontal axis are years for available data. Solid red and black lines are IQR and e(5), respectively. 
Figure 8: Interquantile range and life expectancy at age 5, Latin America, 1920-2010, females
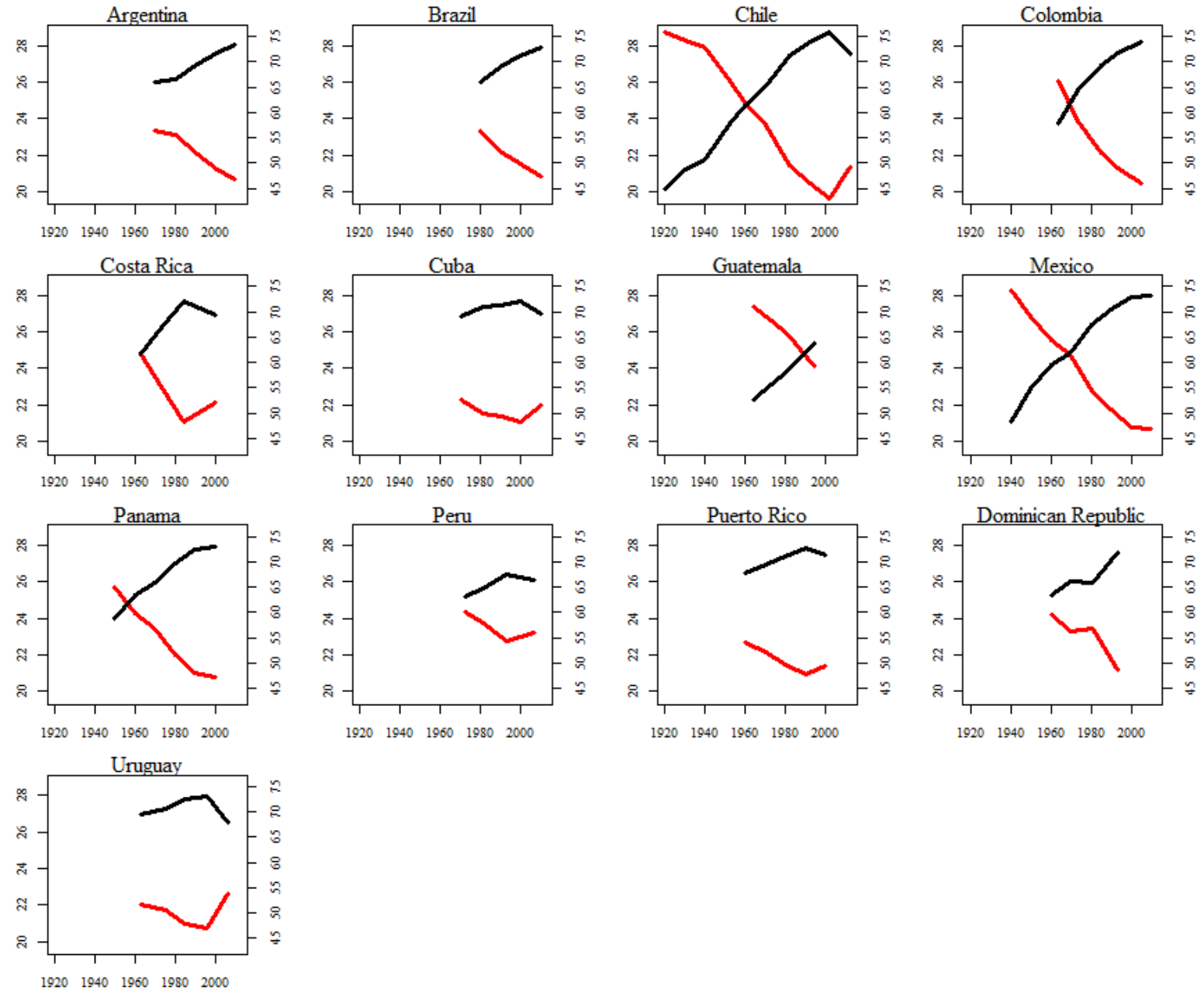

Source: Latin America Human Mortality Database (2014), Human Mortality Database (2014) and World Health Organization Database (2014)

Note: Right and left vertical axis are IQR and Life Expectancy at age 5 - e(5), respectively. Horizontal axis are years for available data. Solid red and black lines are IQR and e(5), respectively. 


\section{Conclusion}

In this article, we evaluate the quality of information on deaths available for a series of Latin America countries in the past half-century. We contributed to the analysis of data quality, following Palloni and Pinto-Aguirre (2011), by producing estimates for males and females separately. The results indicate that the quality of mortality data is improving over time for all countries included in this study, and could be considered of high quality and can be a very useful tool for studies of mortality in Latin America.

We also examined the changes in the mortality pattern of the population in each country in the past few decades to identify changes in the variability of age at death. A reduction in this variability, accompanied by a shift in the distribution of deaths for older ages, would indicate that the process of compression of mortality, observed today in most countries experiencing low levels of mortality, is currently being in progress in Latin America countries. The analysis of reduced variability of age in some developed countries such as Japan and the U.S., indicated that the reduction in variability was also low, as observed for most of Latin America countries. For example, for Japan, between 1961 and 1971 (life expectancy at birth, respectively, 69.4 and 73.5, close to what is observed in Latin America in recent years) and the variation in IQR (17.5 and 15.9, respectively) was 1.60. In the case of USA, between 1951 and 1981 (life expectancy at birth, respectively, 69.1 and 74.5) the variation in IQR (20.6 and 19.4, respectively) was only 1.20.

The analysis by sex indicates that reduction in variability of age at death for females was higher than males in LA countries. This difference in variability of age at death corroborates historical analyzes performed in developing countries. This may be associated with a lower risk exposure or a lower socio-economic heterogeneity and biological among women.

The study of compression of mortality and variability of age at death are very important and contribute to a better understanding of the evolution of health status of the elderly population, especially regarding the duration of active and disable years of life around the age of death. In fact, a reduction in the variability of age at death concomitantly with the increase in the average age of death is of crucial importance 
for public health planners, since the diseases that affect these individuals are chronic, mostly requiring monitoring of conditions of the elderly's health over a long period of time. As pointed by Canudas-Romo (2010) delay mortality implies that a more heterogeneous group of the population is reaching older ages and we can expected that health differential and disparities that are common in early life in Latin America are now moving towards older age groups. In the near future, health systems in Latin America, and families, will have to deal with a larger and more diverse group, regarding health status, at older ages. This might imply larger costs and more complex interventions to mitigate the differences.

Another important aspect to be highlighted is that, according Paccaud et al (1998), given the heterogeneity of mortality among populations, the main issue would be to investigate the extent of variation around the age at death and not the central age of deaths. In this regard, the compression process should be seen also as part of a related improvement in the health state of the elderly. One can argue that the reduction in the "state" of disability and the disease process occurs around the age at death (Paccaud et al, 1998). That is, it would be a process whose origin would, in fact, be the compression of morbidity ( Fries , 1980, 1984). In other words, since the health status of the elderly is improving, with a corresponding increase of the life expectancy free of disability (Cambois , Robine and Hayward , 2001; Baptista , 2003; Camargo , Rodrigues and Machado , 2003; Romero Milk and Szwarcwald , 2005), we would observe an improvement of the conditions at older ages.

The concept of compression of morbidity, as originally proposed by Fries (1980), is based on two assumptions: upper limit to human longevity and delay in age at onset of chronic conditions. Under these assumptions, a trend of significant decline in mortality rates, with the existence of a biological limit to human longevity (Bongaarts and Feeney, 2002), could trigger a process of compression of mortality or rectangularization of the survival curve at older ages (Fries , 1980 ; Wilmoth , 1997; Wilmoth and Horiuchi , 1999). Thus, the original concept of the compression of morbidity, under the assumption of a fixed limit to human longevity, would mean an increase in the average number of years free of disabilities (Fries ,1980; Nusselder, 2003). In this sense, the compression of morbidity would be related to an increase in 
the average age of the onset of chronic conditions in the elderly, leading to people living longer in better health ( Nusselder, 2003) .

An important limitation of the study is related to the data sources used to produce the estimates of survival curves. In addition to the under-registration of death counts in most of the vital registration systems in Latin America, we might find problems with errors in the age declaration of age, which may occur in the source of deaths and population. The tendency to over-state the age is lower in death records compared to live population. In this case, considering that defective age declaration is higher in the census than in the registration of deaths, at advanced ages, where the errors are larger, an over-statement of ages in the census may underestimate the specific mortality rates and the result would be a lower number of estimated deaths at these ages. If the trend in the census is to declare an age lower than the true number of deaths at older ages could be over-estimated, leading to the false impression of a higher concentration of deaths at advanced ages. However, if it is reasonable to assume that the standard errors of the old statement has been roughly constant over time, the results would not be compromised, because the changes in the variability of age at death are related to changes in the structure of mortality and not on their level. An additional limitation refers to the use of period data to estimate compression of mortality in a period of declining mortality. The trends would be better observed if we had available cohort mortality data. But, as pointed by others, our results provide, at least, a conservative measure of the compression of mortality in Latin America.

\section{Bibliography}

ABURTO José Manuel, BELTRÁN-SÁNCHEZ Hiram, GARCÍA-GUERRERO Victor Manuel; CANUDAS-ROMO Vladimir, 2016, "Homicides In Mexico Reversed Life Expectancy Gains For Men And Slowed Them For Women 2000-10", Health Affairs, 35(1), pp 88-95.

ALBALA Cecilia, SÁNCHEZ Hugo, LERA Lydia, ANGEL Barbara, CEA Ximena, 2011, "Efecto sobre la salud de las desigualdades socioeconómicas en el adulto mayor. Resultados basales del estudio expectativa de vida saludable y discapacidad relacionada con la obesidad (Alexandros)", Rev Med Chile; 139, pp 1276-1285.

ARAÚJO José, 2012, "Polarização epidemiológica no Brasil", Epidemiol. Serv. Saúde, 21(4), pp 533-538. 
BERGERON-BOUCHER Marie-Pier; EBELING Marcusl; CANUDAS-ROMO Vladimir, 2015, "Decomposing changes in life expectancy: Compression versus shifting mortality", Demographic Research, 33(14), pp 391-424.

BOBAK Martin, MALYUTINA Sofia, HORVAT Pia, PAJAK Andrzej, TAMOSIUNAS Abdonas, KUBINOVA Ruzena, SIMONOVA Galina, TOPORMADRY Roman, PEASEY Anne, PIKHART Hynek, MARMOT Michael , 2016, "Alcohol, drinking pattern and all-cause, cardiovascular and alcohol-related mortality in Eastern Europe", European journal of epidemiology, 31, pp 21.

BONGAARTS John, 2005, "Long-range trends in adult mortality: Models and projection methods“, Demography, 42(1), pp. 23-49.

BONGAARTS John, FEENEY Griffith, 2002, “How long do we live?”, Population and Development Review, 28(1), pp.13-29.

BONGAARTS John, FEENEY Griffith, 2003, "Estimating mean lifetime", Proceedings of the National Academy of Sciences, 100(23), pp.13127-13133.

BREVIS Cecilia, DEL RÍO Fernando, YANEZ Mabel, 1997, “Transición epidemiológica en América Latina: comparación de cuatro países", Rev. méd. Chile, 125(6), pp. 719-27.

CANUDAS-ROMO Vladimir, 2008, "The modal age at death and the shifting mortality hypothesis", Demographic Research, 19(30), pp. 1179-1204.

CANUDAS-ROMO Vladimir, 2010, "Three measures of longevity: Time trends and record values", Demography, 47(2), pp. 299-312.

CANUDAS-ROMO Vladimir, GARCÍA-GUERRERO Víctor, 2013, "The Stagnation of the Mexican Life Expectancy in the First Decade of the Twenty First Century: The Impact of Violent Deaths", Paper presented at the 2013 Meeting of International Union for the Scientific Study of Population, Busan, South Korean.

Centro Latinoamericano y Caribeño de Demografía. América Latina: Tablas de mortalidad, 1950-2025. Bol Demográfico. 2004;74:1-344

CHAIMOWICZ Flavio, 1997, “A saúde dos idosos brasileiros às vésperas do século XXI: problemas, projeções e alternativas“, Rev. Saúde Pública, 31(2), pp. 184-200.

CHEUNG Siu Lan, ROBINE Jean-Marie, 2007, "Increase in common longevity and the compression of mortality: The case of Japan“, Population Studies, 61(1), pp. 8597.

CHEUNG Siu Lan, ROBINE Jean-Marie, JOW-CHING TU Edward, CASELLI Graziella, 2005, "Three dimensions of the survival curve: horizontalization, verticalization, and longevity extension", Demography, 42(2), pp. 243-258.

CUTLER David, DEATON Angus, LLERAS-MUNEY Adriana, 2006, "The determinants of mortality”, Journal of Economic Perspectives, 20(6), pp. 97-120.

CUTLER David, MILLER Grant, 2005, "The role of public health improvements in health advances: The Twentieth-Century“, Demography, 42(1), pp. 1-22.

JORGE Maria, LAURENTI Ruy, LÉA Sabina, GOTLIEB Davidson, 2007, "Análise da qualidade das estatísticas vitais brasileiras: a experiência de implantação do SIM e do SINASC", Ciência e Saúde Coletiva, 12 (3), pp 643-654. 
EDWARDS Ryan, TULJAPURKAR Shripad, 2005 "Inequality in Life Spans and a New perspective on mortality convergence across industrialized countries", Population and Development Review, 31(4), pp 645-74.

ENGELMAN Michal, CANUDAS-ROMO Vladimir, AGREE Emily, 2010, "The implications of increased survivorship for mortality variation in aging populations.", Population and Development Review, 36(3), pp 511-539.

ENGELMAN Michal, CASWELL Hal, AGREE Emily, 2014, "Why do lifespan variability trends for the young and old diverge? A perturbation analysis", Demographic Research, 30(48), pp 1367-1396.

FOGEL, Robert W, 1986, "Nutrition and the decline of mortality since 1700: some preliminary findings", in Engerman Stanley and Gallman Robert (eds.), Long-Term Factors in American Economic Growth, Chicago: University of Chicago Press, pp $439-556$.

FRENK Julio, FREJKA Tomas, BOBADILLA J L, STERN C, LOZANO Rafael, SEPÚLVEDA Jaime, JOSÉ Marco V, 1991, “The epidemiologic transition in Latin America”, Bol Oficina Sanit Panam.,111(6), pp 485-96.

FRIES James F, 1980, “Aging, natural death, and the compression of mortality”, The New England Journal of Medicine, 303(3), pp 130-135.

GO Charles, BRUSTROM Jennifer, LYNCH Margaret., ALDWIN Carolyn, 1995, "Ethnic trends in survival curves and mortality", The Gerontologist, 35(3), pp 318326.

GONZAGA Marcos Roberto, QUEIROZ Bernardo, MACHADO Carla, 2009, "Compression of mortality: a study on the variability of age at death in the State of São Paulo", Cad. Saúde Pública, 25(7), pp 1475-1485.

HILL Kenneth, 1987, "Estimating census and death registration completeness.", Asian and Pacific Census Forum, 1(3), pp 8-24.

HILL Kenneth., YOU Danzhen, CHOI Yoonjoung, 2009, "Death Distribution Methods for Estimating Adult Mortality: sensitivity analysis with simulated data errors", Demographic Research, 21(9), pp 235-254.

HILL Kenneth, CHOI Yoonjoung, TIMAEUS Ian, 2005, "Unconventional approaches to mortality estimation. Demographic Research", 13(12), pp 281-300.

HIMES Christine, PRESTON Samuel, CONDRAN Gretchen, 1994, "A Relational Model of Mortality at Older Ages in Low Mortality Countries.", Population Studies, 48(2), pp 240-291.

HORIUCHI S, 1999, "Epidemiological transitions in developed countries: past, present and future.", In: UNITED NATIONS. Health and mortality issues of global concern. Proceedings of the Symposium on Health and Mortality. Chap. 2: 54-71. Brussels, 19-22 November. New York: United Nations.

Instituto Brasileiro de Geografia e Estatística (IBGE), Censo Demográfico 19102000. Até 1981, dados extraídos de Estatística do Século XX, IBGE : Rio de Janeiro, 2007 no Anuário Estatístico do Brasil, 1981, vol 42, 1981.

Instituto Brasileiro de Geografia e Estatística (IBGE), ed. 2013. Tábuas abreviadas de mortalidade por sexo e idade: Brasil, grandes regiões e unidades da Federação, 2010. 
Estudos e pesquisas. Informação demográfica e socioeconômica. Rio de Janeiro: Instituto Brasileiro de Geografia e Estatística - IBGE.

KANNISTO Väinö, 2000, "Measuring the compression of mortality." Demographic Research 3(6), pp 24.

Latin American Human Mortality Database. B. Piedad Urdinola and Bernardo L. Queiroz . Available at www.lamortalidad.org (data downloaded on [23/07/2016]).

MCKEE Martin, SHKOLNIKOV Vladimir, 2001, "Understanding the toll of premature death among men in eastern Europe.”, British Medical Journal, 323(7320), pp 1051-5.

MCKEOWN Thomas, RECORD R.G, 1962, "Reasons for the decline of mortality in England and Wales during the 19th century". Population Studies, 16(2), pp 94-122.

MEYERS George, MANTON Kenneth, 1984, "Compression of mortality: myth or reality?", The Gerontologist, 24(4), pp 346-353.

MEYERS George, MANTON Kenneth, 1984, "Recent Changes in the U. S. Age at Death Distribution: Further Observations", The Gerontologist, 24(6), pp 572-575.

NADANOVSKY Paulo, CELESTE Roger, WILSON Margo, DALY Martin, 2009, "Homicide and impunity: an ecological analysis at state level in Brazil", Rev Saúde Pública, 43(5), pp 733-42.

NUSSELDER Wilman, MACKENBACH Johan, 1996, "Rectangularization of the Survival Curve in the Netherlands, 1950-1992", The Gerontologist, 36(6), pp 773782.

OMRAN Abel, 1982, "Epidemiologic Transition", in International Encyclopedia of Population, New York: The Free Press, pp 172-183.

OMRAN Abel, 1971, "The epidemiologic transition: a theory of the epidemiology of population change", The Milbank Memorial Fund Quarterly, 49(4), pp 509-538.

PACCAUD Fred, PINTO Claudio, MARAZZI Alfio, MILI Judith, 1998, “Age at death and rectangularisation of the survival curve: trends in Switzerland, 1969-1994", Journal of Epidemiology Community Health, 52(7), pp 412-415.

PAES Neir, 2005, "Avaliação da cobertura dos registros de óbitos dos estados brasileiros em 2000” Revista de Saúde Pública, 39(6), pp 882-890.

PALLONI Alberto, 1985, "An Epidemio-Demographic Analysis of Factors in the Mortality Decline of 'slow-developing' countries." In proceedings of the International Population Conference, Florence, International Union for the Scientific Studies of Population, Ordina Press, 2, pp 329-351.

PALLONI Alberto, PINTO-AGUIRRE Guido, 2011, "Adult mortality in Latin America and the Caribbean", in Richard Rogers and Eileen Crimmins (eds.), International Handbook of Adult Mortality, 2(1), pp 101-132.

PALLONI Alberto, MCENIRY Mary, WONG Rebeca, PELAEZ Martha, 2007, "Ageing in Latin America and the Caribbean: Implications of Past Mortality." In: Proceedings of the United Nations Expert Group Meeting on Social and Economic Implications of Changing Population Age Structures, pp. 253-284. August 31September 2, 2005, Mexico City, Mexico 
PALLONI Alberto, HILL Kenneth, PINTO-AGUIRRE Guido, 1996, "Economic Swings and Demographic Changes in the History of Latin America", Population Studies, 50(1), pp 105-132.

PALLONI Alberto, PINTO-AGUIRRE Guido, 2004, "One hundred years of mortality in Latin America and the Caribbean: the fragile path from hunger to longevity." Paper presented at the 2004 Meeting of the Population Association of America Meetings, Boston, Massachusetts.

PALLONI Alberto, WYRICK Randy, 1981,"Mortality decline in Latin America: changes in the structure of causes of deaths, 1950-1975." Biodemography and Social Biology, 28(3-4), pp 187-216.

PALLONI Alberto, 1981, "Mortality in Latin America: emerging patterns." Population and Development Review, 7(4), pp 623-649.

PRESTON Samuel, 1975, "The changing relation between mortality and level of economic development”, Population Studies, 29(2), pp 231-48.

QUEIROZ Bernardo, FREIRE Flávio; LIMA Everton; GONZAGA Marcos, 2017. "Completeness of death-count coverage and adult mortality (45q15) for Brazilian states from 1980 to 2010", Rev Bras Epidemiol; 20(1), pp: 21-33.

SCHRAMM Joyce, OLIVEIRA Andreia; LEITE Iúri; VALENTE Joaquim, GADELHA Ângela, PORTELA Margareth; CAMPOS Mônica, 2004, "Transição epidemiológica e o estudo de carga de doença no Brasil”, Ciência and Saúde Coletiva, 9(4), pp:897-908.

VAN RAALTE Alyson, CASWELL Hal, 2013, "Perturbation analysis of indices of lifespan variability.", Demography, 50(5), pp 1615-40.

WAISELFISZ Julio, 2012, Mapa da violência 2012: a cor dos homicídios no Brasil Brasília: RITLA/Instituto Sangari/Ministério da Saúde/Ministério da Justiça.WAISELFISZ, J.J. Mapa da Violência 2013: Homicídios e Juventude no Brasil. FLACSO, Brasília, Brasil.

WILMOTH John, 1997,. "In search of limits", in Kenneth W Wachter and Caleb E Finch. (eds.), Between Zeus and The Salmon: The Biodemography of Longevity, Washington, DC: National Academy Press, pp 38-64.

WILMOTH John., HORIUCHI Shiro,1999, "Rectangularization revisited: Variability of age at death within human populations", Demography, 36(4), pp 475495.

ZARIDZE David et al., 2014, "Alcohol and mortality in Russia: prospective observational study of 151000 adults", The Lancet, 383(9927), pp 1465-1473.

ZUREICK, Sarah ,2010, "Certainty in Timing of Death: A New Analysis of Shifting Mortality and Life Span Disparity", Ph.D dissertation, Department of Demography University of California, Berkeley. 


\section{Acknowledgments}

Financial support from Fapemig - Programa Pesquisador Mineiro - and CNPq is gratefully acknowledged by Bernardo L. Queiroz. This research was funded by CNPq - Edital de Ciências Sociais (2011-2013). Support from São Paulo Research Foundation - FAPESP - grand 2014/05129-4 is gratefully acknowledged by Everton E.C. Lima. 
Table A.1 - Countries, Periods Covered and Estimates of Completeness of Death Counts, Latin America, Males and Females

\begin{tabular}{|c|c|c|c|}
\hline Country & Intercensus period & Males & Females \\
\hline Argentina & $1960-1970$ & 1.99 & 2.20 \\
\hline Argentina & $1970-1980$ & 0.77 & 0.46 \\
\hline Argentina & $1980-1991$ & 1.03 & 1.14 \\
\hline Argentina & $1991-2000$ & 1.00 & 1.00 \\
\hline Argentina & $2000-2010$ & 1.00 & 1.00 \\
\hline Brasil & $1980-1991$ & 0.84 & 0.76 \\
\hline Brasil & $1991-2000$ & 0.95 & 0.90 \\
\hline Brasil & $2000-2010$ & 0.98 & 0.96 \\
\hline Chile & $1920-1930$ & 1.15 & 1.22 \\
\hline Chile & $1930-1940$ & 1.15 & 1.23 \\
\hline Chile & $1940-1952$ & 1.14 & 1.39 \\
\hline Chile & $1952-1960$ & 1.16 & 1.23 \\
\hline Chile & $1960-1970$ & 1.23 & 1.26 \\
\hline Chile & $1970-1982$ & 1.13 & 1.14 \\
\hline Chile & $1982-1992$ & 1.07 & 1.07 \\
\hline Chile & $1992-2002$ & 1.00 & 1.00 \\
\hline Chile & $2002-2012$ & 1.00 & 1.00 \\
\hline Colombia & 1951-1964 & 1.35 & 1.74 \\
\hline Colombia & $1964-1973$ & 0.98 & 1.02 \\
\hline Colombia & $1973-1985$ & 1.09 & 1.14 \\
\hline Colombia & $1985-1993$ & 1.11 & 1.03 \\
\hline Colombia & $1993-2005$ & 0.98 & 1.12 \\
\hline Costa Rica & $1951-1963$ & 0.70 & 0.56 \\
\hline Costa Rica & $1963-1973$ & 0.87 & 0.87 \\
\hline Costa Rica & $1973-1984$ & 0.89 & 0.83 \\
\hline Costa Rica & $1984-2000$ & 1.02 & 1.16 \\
\hline Cuba & $1953-1970$ & 1.34 & 1.41 \\
\hline Cuba & $1970-1981$ & 1.05 & 1.01 \\
\hline Cuba & 1981-1993 & 0.98 & 0.98 \\
\hline Cuba & $1993-2002$ & 1.00 & 1.00 \\
\hline Dominican Republic & $1950-1960$ & 0.81 & 1.19 \\
\hline Dominican Republic & $1960-1970$ & 0.67 & 0.86 \\
\hline Dominican Republic & $1970-1981$ & 1.07 & 1.23 \\
\hline Dominican Republic & 1981-1993 & 1.22 & 0.87 \\
\hline
\end{tabular}




\begin{tabular}{|c|c|c|c|}
\hline Guatemala & $1950-1964$ & 1.38 & 1.49 \\
\hline Guatemala & $1964-1973$ & 1.10 & 1.11 \\
\hline Guatemala & $1973-1981$ & 1.30 & 1.31 \\
\hline Guatemala & 1981-1994 & 1.31 & 1.33 \\
\hline Mexico & $1930-1940$ & 1.10 & 1.26 \\
\hline Mexico & $1940-1950$ & 1.35 & 1.51 \\
\hline Mexico & $1950-1960$ & 1.20 & 1.28 \\
\hline Mexico & $1960-1970$ & 1.13 & 1.37 \\
\hline Mexico & $1970-1980$ & 1.10 & 1.19 \\
\hline Mexico & $1980-1990$ & 1.11 & 1.15 \\
\hline Mexico & $1990-2000$ & 1.00 & 0.98 \\
\hline Mexico & $2000-2010$ & 1.00 & 1.00 \\
\hline Panama & $1950-1960$ & 1.23 & 1.00 \\
\hline Panama & 1960-1970 & 1.03 & 1.07 \\
\hline Panama & $1970-1980$ & 0.91 & 0.99 \\
\hline Panama & 1980-1990 & 0.92 & 0.89 \\
\hline Panama & $1990-2000$ & 0.87 & 0.87 \\
\hline Panama & $2000-2010$ & 1.00 & 1.00 \\
\hline Peru & $1961-1972$ & 1.05 & 1.10 \\
\hline Peru & $1972-1981$ & 0.83 & 0.78 \\
\hline Peru & 1981-1993 & 0.72 & 0.73 \\
\hline Peru & 1993-2005 & 0.77 & 0.81 \\
\hline Puerto Rico & $1960-1970$ & 1.39 & 1.72 \\
\hline Puerto Rico & $1970-1980$ & 1.99 & 1.23 \\
\hline Puerto Rico & $1980-1990$ & 1.28 & 1.20 \\
\hline Puerto Rico & $1990-2000$ & 1.16 & 1.05 \\
\hline Puerto Rico & $2000-2010$ & 1.00 & 1.00 \\
\hline
\end{tabular}

Source: Latin America Human Mortality Database (2014), Human Mortality Database (2014) and World Health Organization Database (2014) 